\title{
Pulmonary capillary haemangiomatosis coexistence with sinus venosus ASD: morphometric analysis and literature review
}

\author{
B.S. Slovis*, I. Chazova+, J.E. Loyd*, B.O. Meyrick**
}

\begin{abstract}
Pulmonary capillary haemangiomatosis coexistence with sinus venosus ASD: morphometric analysis and literature review. B.S. Slovis, I. Chazova, J.E. Loyd, B.O. Meyrick. CERS Journals Ltd 1998.

ABSTRACT: A 24 yr old white female presented with dyspnoea, orthopnoea, paroxysmal nocturnal dyspnoea, cough and fatigue. Transthoracic echocardiography revealed a sinus venosus atrial septal defect (ASD). Right heart catheterization confirmed severe pulmonary hypertension $(80 / 37 \mathrm{mmHg})$. A chest radiograph showed enlarged pulmonary arteries with peripheral pruning. Surgical repair of the ASD and lung biopsy were performed. Two days later, she developed right heart failure and was treated with inhaled nitric oxide and then a calcium channel blocker. She failed to improve and was readmitted three months later with severe right heart failure and progressive dyspnoea. While waiting for lung transplantation, she developed haematochezia and died. Light microscopy of lung biopsy and autopsy tissue revealed the structural changes of pulmonary hypertension and focal increases in congested pulmonary capillaries consistent with the diagnosis of pulmonary capillary haemangiomatosis. Quantitative analysis demonstrated that the pathological changes were rapidly progressive.

Eur Respir J 1998; 12: 240-244.
\end{abstract}

*Division of Pulmonary and Critical Care Medicine, **Dept of Pathology, Vanderbilt University School of Medicine, Nashville, Tennessee, USA. +Cardiology Research Complex, Moscow, Russia.

Corresponding: B. Meyrick, Center for Lung Research, T-1217 Medical Center North, Vanderbilt University, Nashville, TN 372322650, USA, Fax: 6153437448

Keywords: Pulmonary artery

pulmonary vein

quantitation

Received: July 241997

Accepted after revision January 151998

This work was supported by HL 48536 , HL 48164 and HL 07123 from the National Heart Lung and Blood Institute, National Institutes of Health.

Pulmonary capillary haemangiomatosis $(\mathrm{PCH})$ is a rare vascular abnormality confined to the lung which results in the development of chronic pulmonary hypertension. It is a fatal disease which is difficult to diagnose antemortem because the clinical features may be identical to those of primary pulmonary hypertension (PPH) or pulmonary venoocclusive disease (PVOD). It is a histological diagnosis based on the presence of numerous foci of proliferating thin walled capillaries which invade lung alveolar tissue, pleura, and bronchial and vascular walls. Since this lesion was first described by WAGENVORT and co-workers in [1] 1978, 23 cases have been reported in the literature, 17 of which were diagnosed at autopsy, making the actual prevalence of PCH difficult to estimate [1-15] (table 1). The aetiology of this disease is unknown. Most cases are sporadic, although LANGLEBEN and co-workers [7] described a

Table 1. - Pulmonary capillary haemangiomatosis: case reports

\begin{tabular}{|c|c|c|c|c|c|c|}
\hline \multicolumn{2}{|l|}{ Reference } & \multirow{2}{*}{$\frac{\text { Age at Death/Sex }}{71 \mathrm{~F}}$} & \multirow{2}{*}{$\begin{array}{c}\text { Haemoptysis } \\
+\end{array}$} & \multirow{2}{*}{$\begin{array}{c}\text { Haemothorax } \\
+\end{array}$} & \multirow{2}{*}{$\frac{\text { Perfusion }}{\text { NA }}$} & \multirow{2}{*}{$\frac{\text { CXR Infil }}{+}$} \\
\hline WAGENVOORT et al. 1978 & {$[1]$} & & & & & \\
\hline WhITTAKER et al. 1983 & [2] & $17 \mathrm{M}$ & + & + & ABNL & + \\
\hline HEATH and ReID et al. 1985 & [3] & $51 \mathrm{~F}$ & NA & NA & ABNL & + \\
\hline MAGEE et al. 1985 & [4] & $41 \mathrm{~F}$ & - & - & ABNL & + \\
\hline \multirow[t]{3}{*}{ TRON et al. 1986} & [5] & $21 \mathrm{~F}$ & - & - & ABNL & + \\
\hline & & $14 \mathrm{M}$ & NA & NA & NA & + \\
\hline & & $38 \mathrm{~F}$ & - & - & ABNL & NA \\
\hline WAGENAAR et al. 1988 & [6] & $12 \mathrm{~F}$ & + & - & ABNL & + \\
\hline LANGLEBEN et al. 1988 & [7] & $30 \mathrm{~F}$ & - & - & ABNL & - \\
\hline \multirow[t]{2}{*}{ (familial) } & & $20 \mathrm{M}$ & - & - & NL & - \\
\hline & & $20 \mathrm{M}$ & - & - & NA & - \\
\hline VeVAINA and Mark 1988 & [8] & $25 \mathrm{~F}$ & - & - & NA & + \\
\hline Wніте et al. 1989 & [9] & $12 \mathrm{M}$ & + & - & ABNL & + \\
\hline \multirow[t]{3}{*}{ FABER et al. 1989} & [10] & $30 \mathrm{~F}$ & + & - & NL & + \\
\hline & & $19 \mathrm{M}$ & + & - & ABNL & + \\
\hline & & $29 \mathrm{M}$ & + & - & NA & - \\
\hline Rush et al. 1991 & [11] & $56 \mathrm{M}$ & - & - & ABNL & - \\
\hline Русоск et al. 1994 & [12] & $60 \mathrm{~F}$ & - & - & NL & - \\
\hline ELTORKY et al. 1994 & [13] & $27 \mathrm{M}$ & + & + & NL & + \\
\hline AL-FAWAZ et al. 1995 & [14] & $12 \mathrm{~F}$ & - & - & ABNL & - \\
\hline MASUR et al. 1996 & [15] & $19 \mathrm{M}$ & - & - & NA & + \\
\hline
\end{tabular}

NA: not available; ABNL: abnormal; NL: normal; Infil: infiltrate; M: male; F: female; CXR: chest radiograph. +: present; -: absent. 
family with three siblings who had pulmonary hypertension, proven histologically to be caused by $\mathrm{PCH}$ in two. Pulmonary haemangiomatoid lesions may be found also in conditions such as cystic fibrosis, sleep apnoea-obesity ventilation syndrome and PVOD [16-18].

We report here a case of $\mathrm{PCH}$ documented to coexist with a sinus venosus atrial septal defect (ASD) and present a detailed morphometric analysis of the pulmonary vasculature showing significant histological progression of disease from the time of lung biopsy to autopsy four months later. We also review the literature and summarize the clinical features of this disease which might prompt further diagnostic evaluation. Early diagnosis is important because of recent hope for successful therapy, demonstrated by regression of disease and improved symptoms in two patients treated with interferon- $\alpha 2[9,19]$, as well as prompting rapid evaluation for lung transplantation for patients with this rapidly progressive illness.

\section{Clinical history}

A 24 yr old white female was referred from her local hospital on 14 January 1994 with a six month history of increasing dyspnoea on exertion, orthopnoea, paroxysmal nocturnal dyspnoea, nonproductive cough, and fatigue. She denied haemoptysis. She reported that she had felt completely well as recently as the previous year and had played in a competitive softball league the prior summer. Cardiac catheterization in her local hospital revealed a mean pulmonary artery pressure of $49 \mathrm{mmHg}$ and a pulmonary capillary wedge pressure of $14 \mathrm{mmHg}$. After diuretic therapy was begun, she improved symptomatically and was transferred to Vanderbilt University Hospital for further evaluation.

A transthoracic echocardiogram revealed a sinus venosus ASD. Repeat right heart catheterization confirmed severe pulmonary hypertension $(80 / 37 \mathrm{mmHg})$ and a partial anomalous right pulmonary vein which returned to the superior vena cava, an anomaly which often occurs with sinus venosus ASD. Her chest radiograph demonstrated enlarged pulmonary arteries with peripheral pruning, a normal cardiac silhouette, and no evidence of lung infiltrates or pleural effusion. Abnormalities were not identified on ventilation perfusion scan or pulmonary arteriogram. Quantitative cinecardiac magnetic resonance imaging (MRI) revealed that the stroke volume of the left ventricle was $49 \mathrm{~mL}$; the right ventricle was $86 \mathrm{~mL}$ with a calculated left-to-right shunt of $37 \mathrm{~mL} \cdot$ stroke $^{-1}$. MRI showed no pulmonary infiltrate or abnormal interstitial markings.

One month later, surgical repair was advised on the basis of: a total pulmonary resistance of $14 \mathrm{U} \cdot \mathrm{m}^{2}$ that was within the range $\left(<15 \mathrm{U} \cdot \mathrm{m}^{2}\right)$ previously described possibly to benefit from ASD repair [19], persistent significant left-to-right shunt, and Heath and Edwards Grade II pulmonary arterial vascular changes (see below) and documentation of a modest decrease in her pulmonary arterial pressures with nitrovasodilators. She underwent successful surgical repair of her septal defect and at surgery the sinus venosus defect and anomalous right pulmonary venous return to the superior vena cava were confirmed. Two days postoperative, she developed severe right ventricular failure and was treated with inhaled nitric oxide (30 parts per million (ppm)) under an investigational protocol. She responded favourably to inhaled nitric oxide and was wean- ed as treatment was begun with a calcium channel blocker. She was discharged home on the eleventh hospital day on oxygen at $4 \mathrm{~L} \cdot \mathrm{min}^{-1}$ by nasal cannula and an oral calcium channel blocker.

Her clinical condition failed to improve, and she was readmitted 3 months later because of progressive dyspnoea at rest and worsening symptoms of right heart failure. While awaiting lung transplantation, she developed haematochezia and died. Clinically, it was believed that she suffered intestinal ischaemia secondary to inadequate cardiac output.

\section{Materials and methods}

Lung tissue samples from both lung biopsy and from autopsy were fixed in $10 \%$ formol-saline and processed for routine light microscopic examination. Five micrometer sections were cut. One section was stained with haematoxylin and eosin, and additional sections were stained with either Masson's pentachrome stain, Gordon and Sweet's method for reticulin fibres or Verhoeff's elastin stain followed by Van Gieson.

Morphometric assessment was made of the structure of the walls of the pulmonary arteries and veins as described previously [20]. In brief, intimal, medial, and adventitial thickness, as well as external diameter, were measured in at least 60 arteries and 30 veins from each of the biopsy and autopsy samples using an eyepiece reticle. Only arteries and veins cut in true cross-section or in oblique section, where the length of the profile was less than twice its diameter, were included. Intimal thickness (IT) was measured from the luminal surface to the luminal edge of the internal elastic lamina for arteries and from the luminal surface to the luminal edge of the single elastic lamina for veins. Adventitial thickness (AT) was measured from the outside of the external or single elastin lamina to the edge of the collagenous connective tissue sheath. Medial thickness (MT) was measured only for arteries and included the muscle coat and internal and external elastic laminae. The thickness of each vascular coat was related to external diameter using the formula: $2 \times(\mathrm{IT}, \mathrm{AT}$ or MT)/external diameter $\times 100$. Arteries and veins were then grouped in the following size ranges $\partial 50,51-100,101-200,201-$ $500,501-1000$, and $>1000 \mu \mathrm{m}$. The mean and standard error of the mean (mean \pm SEM) was then calculated for each size range for both the biopsy and autopsy specimens.

The widespread nature and progression of the haemangiomatous lesions from biopsy to autopsy was evaluated using a $\times 10$ objective and an eyepiece reticle marked with 25 crosshairs. The number of crosshairs falling over normal alveolar walls and the number falling over abnormal alveolar walls containing several layers of congested capillaries was noted. One hundred consecutive fields were examined. Fields containing structures Š $100 \mu \mathrm{m}$ were not included. In this way, the mean volume density of normal and abnormal alveolar walls was calculated for the biopsy and autopsy samples.

\section{Histological results}

Gross findings at autopsy were evidence of right heart failure without pulmonary artery thrombi, colonic inflammation, and a repaired sinus venosus ASD. The lungs 
were focally firm, with multiple pleural petechial haemorrhages and bilateral serous pleural effusions. The presence of persistent bilateral foetal lobulation of the kidneys was noted, a developmental anomaly reported in one other case of PCH [19].

The most striking histological feature of the autopsy lung tissue was the focal increases in the number of congested capillaries (figs. 1a and 2). Haemosiderin laden alveolar macrophages and occasional regions of fresh haemorrhage were present. Increased thickness of the arterial walls was also apparent, as was the appearance of muscle in walls of normally nonmuscular arteries (fig. 1b). The focal regions of capillary proliferation were usually closely associated
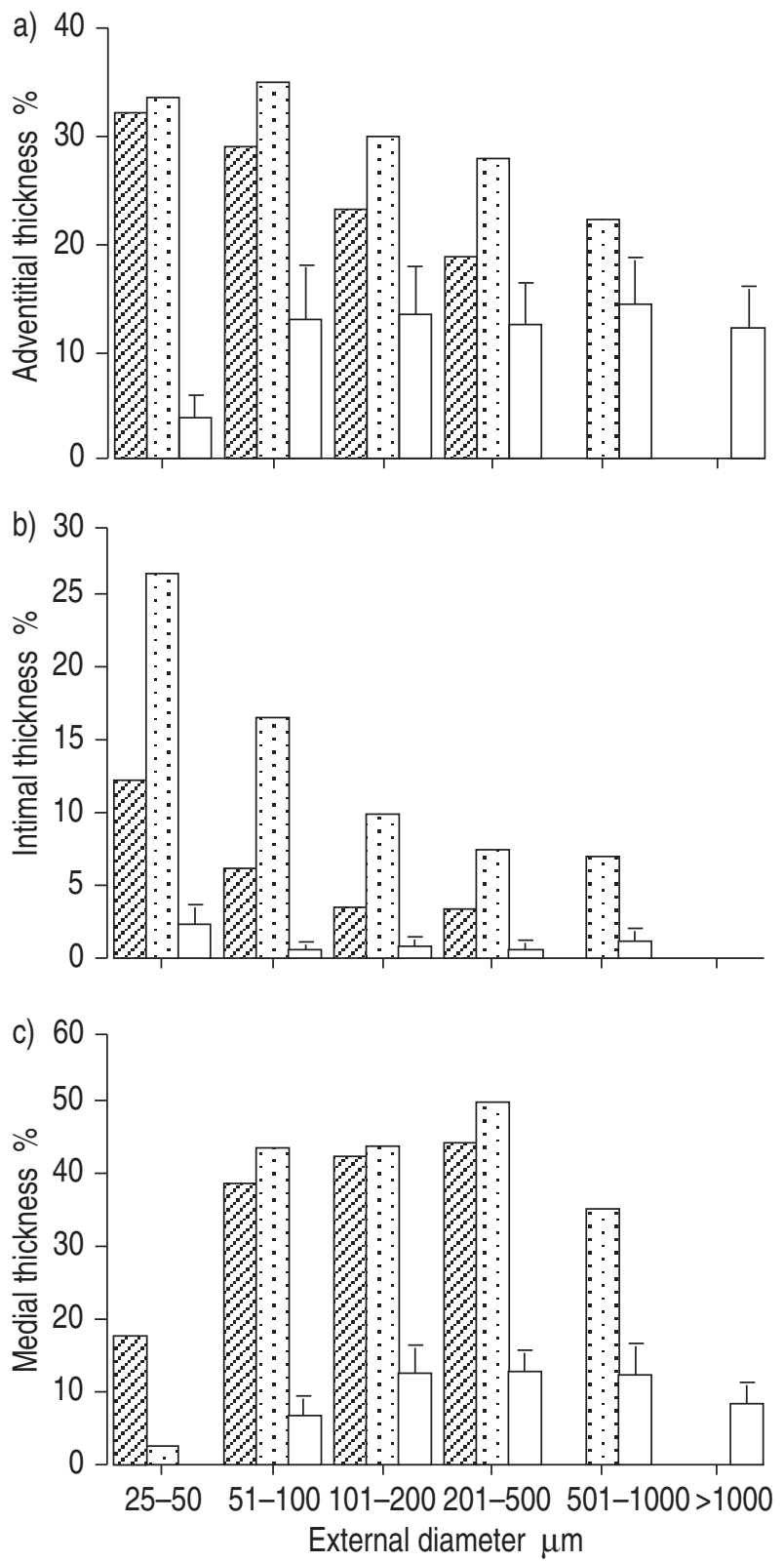

Fig. 1. - Comparison of percentage of a) adventitial; b) intimal; and c) medial thickness of pulmonary arteries of various external diameters from historical controls [20] and from lung biopsy and autopsy tissue obtained 4 months later from a patient with pulmonary capilliary hypertension. Data are shown as mean \pm SEM. $\square$ controls $(n=7)$; $Z$ : biopsy; : autopsy.
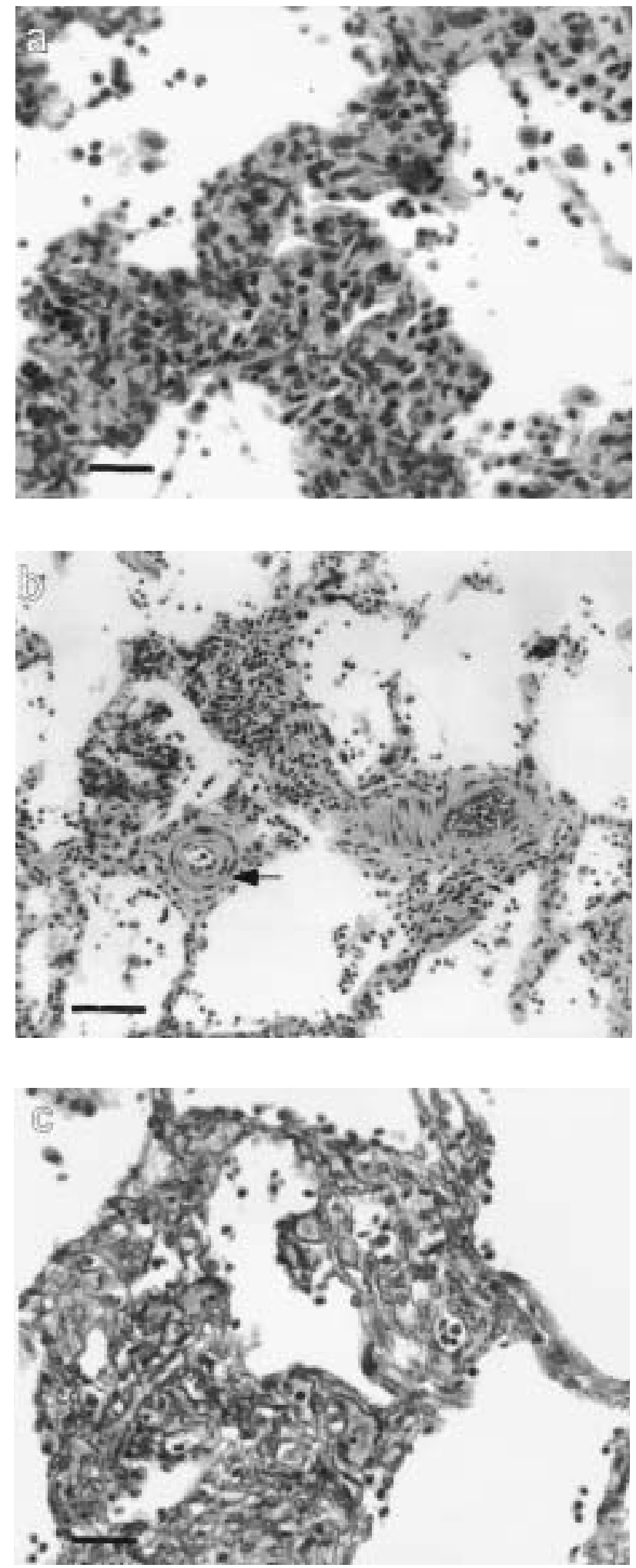

Fig. 2. - Light micrographs of autopsy lung showing a) a haemangiomatoid region with striking capillary proliferation in the thickened alveolar walls (haematoxylin/eosin stain $(\mathrm{H} / \mathrm{E})$, internal scale bar $=20 \mu \mathrm{m}) ; \mathrm{b}$ ) appearance of muscle into normally nonmuscular arteries (arrow) and increased medial thickness of an adjacent artery; the haemangiomatoid lesion to the upper left is adjacent to normal lung tissue $(\mathrm{H} / \mathrm{E}$, internal scale bar $=50 \mu \mathrm{m})$; c) reticulin fibres demarcating the increased number of capillaries in a haemangiomatoid lesion (Gordon and Sweet reticulin stain, internal scale bar $=20 \mu \mathrm{m}$ ) 
with bronchopulmonary bundles as well as pulmonary arteries and veins; occasional venous profiles revealed infiltration of the abnormal capillaries into vein walls. Reticulin fibres in the angiomatous lesions were increased and outlined the expanded number of capillary profiles (fig. 1c). In retrospect, a few capillary nodules were also apparent in the biopsy tissue.

\section{Arterial structure}

In biopsy tissue, percentage medial, adventitial, and intimal thickness were increased for arteries of all size ranges examined when compared with historical controls $(22 ; n$ =7). The most dramatic increases were in the thickness of the media and adventitia (fig. 2). For example, percentage medial thickness for arteries of 101-200 $\mu \mathrm{m}$ external diameter was $21.2 \%$, a value three times the control value. Little evidence of eccentric intimal thickening was noted, but concentric intimal thickening was evident ( $13 \%$ of all arteries examined), particularly in arteries of $<50 \mu \mathrm{m}$ external diameter, where $29 \%$ were affected. Intimal obliteration was not a feature. The presence of muscle in smaller and more peripheral arteries was evident.

Examination of the autopsy lung revealed further small increases in percentage medial and adventitial thickness over the values obtained in the biopsy tissue (fig. 2c). The appearance of muscle into smaller arteries than normal was less than in the biopsy tissue, perhaps because of a loss of small arteries (fig. 2b). Percentage intimal thickness, however, showed a striking additional increase, which was particularly prominent in the smaller arteries of $<200 \mu \mathrm{m}$ (fig. 2a). For example, percentage intimal thickness for arteries $<50 \mu \mathrm{m}$ in the autopsy lung was $53 \%$ compared to $24.3 \%$ in the biopsy tissue. Examination of the autopsy lung also revealed the appearance of eccentric intimal thickening in arteries of $<1,000 \mu \mathrm{m}$ when it was $20 \%$, whereas the proportion of concentric intimal thickening was increased to $31 \%$ for arteries of all external diameters when compared with biopsy tissue, $81 \%$ of the affected arteries being $<50 \mu \mathrm{m}$.

\section{Venous structure}

Both venous intimal and adventitial thickness were increased in the biopsy tissue (fig. 3). Intimal thickness was approximately three times greater than historical controls [22] and adventitial thickness was approximately doubled. Approximately one-sixth of the veins showed concentric intimal thickening. Neither eccentric intimal thickening nor venous occlusion were found.

Intimal thickness showed a twofold increase in the autopsy lung samples when compared with the biopsy tissue (42 versus $20 \%$ ), and adventitial thickness also showed a further but more modest increase (38 versus $30 \%$ ). An additional increase was also noted in the number of arteries demonstrating concentric intimal thickness when more than half of the veins examined showed this change (83 versus $30 \%$ ). Evidence of eccentric thickening or venous obliteration was not found.

\section{Haemangiomatous lesions}

Quantitation of the haemangiomatous lesions in the biopsy tissue revealed that $22.4 \pm 22.8 \%$ (mean \pm sD) of the alveolar wall was affected and the remaining $77.6 \%$ of the walls were of normal appearance. In the autopsy tissue, haemangiomatous lesions were more numerous and diffuse; quantitation revealed that $44.6 \pm 28.4 \%$ of the alveolar walls were now affected by these lesions and $55.4 \%$ were normal.

\section{Discussion}

Pulmonary capillary haemangiomatosis is an organspecific vascular proliferation that results in the development of chronic pulmonary hypertension. Although PCH is not a malignant neoplasm histologically, it is locally infiltrative and uniformly fatal. Our data suggest that its growth and spread is rapid. White et al. [21] described two types of pulmonary haemangiomatosis: the cavernous type, which most commonly affects younger patients and results in death from haemorrhage, and the capillary type, which affects older children and adults and results in death from complications of pulmonary hypertension. They also reported regression of disease and symptomatic improvement in two paediatric patients with $\mathrm{PCH}$ who were treated with recombinant interferon- $\alpha 2[21,22]$. While lung biopsy is generally not required in the evaluation of patients with $\mathrm{PPH}$, because alternative diagnoses made by biopsy are uncommon [23], the reports that interferon might be an effective therapy for PCH may be an important consideration in determining the need for biopsy. Our experience demonstrates that the diagnosis of $\mathrm{PCH}$ from a limited biopsy specimen is difficult given the patchy nature of the disease. Obtaining large lung specimens from multiple sites may minimize this problem.

Other authors have suggested that haemoptysis, haemothorax, a reticulonodular pattern on chest radiograph or an abnormal appearance on ventilation perfusion scanning should raise the suspicion of $\mathrm{PCH}$ in a patient with pulmonary hypertension of unknown aetiology. While we agree that these findings are suggestive, it is important to note that in our review of 21 reported cases, haemoptysis was documented in only eight (38\%) patients, abnormal interstitial pattern on chest radiographs in $13(62 \%)$, haemothorax with bloody pleural effusion in three (14\%) and abnormalities on perfusion scan in nine (43\%). Our case is an example of a patient who demonstrated none of these clinical clues to the underlying pathology. Her lung appeared normal even by more sophisticated imaging with computed tomography and MRI scanning. Furthermore, the coexistent ASD was initially believed to be the cause of her life-threatening pulmonary hypertension.

The present quantitative comparison of biopsy tissue to autopsy tissue taken 4 months later from a patient with $\mathrm{PCH}$ has allowed us to document the progression of the structural changes in the walls of both the pulmonary arteries and veins and the proliferation of haemangiomatous lesions in the peripheral lung using quantitative techniques. At autopsy, the lung exhibited the classic features of pulmonary haemangiomatosis: widespread haemangiomatosis in the alveolar walls with occasional infiltration by these abnormal capillaries into the walls of pulmonary vessels increased numbers of haemosiderin laden alveolar macrophages, and scattered areas of fresh alveolar haemorrhage. A rapid increase in the number of haemangiomatous lesions over a four month period was also demonstrated. 
Further, striking increases in thickness of the intimal layers of both the arteries and veins were noted with resultant severe luminal narrowing. These latter findings, coupled with obstruction of normal capillaries in half of the capillary bed, doubtless contribute to the progression of chronic pulmonary hypertension.

In summary, pulmonary capillary haemangiomatosis may cause life-threatening pulmonary hypertension in the absence of any of the previously described clinical clues, such as haemoptysis, haemothorax, interstitial infiltrates, or perfusion abnormalities. To our knowledge, this is the first morphometric analysis of the lungs of a patient with pulmonary capillary haemangiomatosis and sinus venosus atrial septal defect and the first report to document progression of the disease. This quantitative approach demonstrated increasing severity of medial, adventitial, and intimal thickening in pulmonary arteries and veins and rapid progression of the angiomatous lesions during the 4 months between lung biopsy and autopsy.

\section{References}

1. Wagenvoort CA, Beetstra A, Spijder J. Capillary haemangiomatosis of the lungs. Histopathology 1978; 2: 401406.

2. Whittaker JS, Pickering CAC, Heath D, Smith P. Pulmonary capillary haemangiomatosis. Diag Histopathol 1983; 6: 77-84.

3. Heath D, Reid R. Invasive pulmonary haemangiomatosis. Br J Dis Chest 1985; 79: 284-294.

4. $\quad$ Magee F, Wright JL, Kay JM, Peetz D, Donevan R, Churg A. Pulmonary capillary hemangiomatosis. Am Rev Respir Dis 1985; 132: 922-925.

5. Tron V, Magee F, Wright J, Colby T, Churg A. Pulmonary capillary hemangiomatosis. Human Pathol 1986; 17: 144 150.

6. Wagenaar SJ, Mulder JJS, Wagenvoort CA, Bosch JM. Brief report: pulmonary capillary haemangiomatosis diagnosed during life. Histopathology 1989; 14: 212-214.

7. Langleben D, Heneghan JM, Batten AP, et al. Familial pulmonary capillary hemangiomatosis resulting in primary pulmonary hypertension. Ann Int Med 1988; 109: 106-109.

8. Vevaina JR, Mark EJ. Thoracic hemangiomatosis masquerading as interstitial lung disease. Chest 1988; 93: 3-6.

9. White CW, Sondheimer HM, Crouch EC, Wilson H, Fan LL. Treatment of pulmonary hemangiomatosis with recombinant interferon alfa-2a. $N$ Engl J Med 1989; 320: 1197-1200.

10. Faber CN, Yousem SA, Dauber JH, Griffith BP, Hardesty
RL, Paradis IL. Pulmonary capillary hemangiomatosis: a report of three cases and a review of the literature. $A m$ Rev Respir Dis 1989; 140: 808-813.

11. Rush C, Langleben C, Schlesinger RD, Stern J, Wang N, Lamoureux E. Lung scintigraphy in pulmonary capillary hemangiomatosis: a rare disorder cousing primary pulmonary hypertension. Clin Nucl Med 1991; 16: 913-917.

12. Pycock CJ, Thomas AJ, Marshall AJ, Scarratt W. Capillary haemangiomatosis: a rare cause of pulmonary hypertension. Respir Med 1994; 88: 153-155.

13. Eltorky MA, Headley AS, Winer-Muram H, Garrett HE, Griffin JP. Pulmonary capillary hemangiomatosis: a clinicopathologic review. Ann Thorac Surg 1994; 57: 772776.

14. Al-Fawaz IM, Al Mobaireek KF, Al-Suhaibani M, Ashour M. Pulmonary capillary hemangiomatosis: a case report and review of the literature. Ped Pulmonol 1995; 19: 243-248.

15. Masur U, Remberger K, Hoeter M. Pulmonary capillary hemangiomatosis as a rare cause of pulmonary hypertension. Pathol Res Pract 1996; 192: 290-295.

16. Tomashefski JF Jr, Konstan MW, Bruce MC, Abramowsky $\mathrm{CR}$. The pathologic characteristics of interstitial pneumonia in cystic fibrosis. Am J Clin Pathol 1989; 91: 522 530 .

17. Ahmed Q, Chung-Park M, Tomashefski JF Jr. Cardiopulmonary pathology in patients with sleep apnea/obesity hypoventilation syndrome. Human Pathol 1977; 28: 264269.

18. Schraufnagel DE, Sekosan M, McGee T, Thakkar MB. Human alveolar capillaries undergo angiogenesis in pulmonary veno-occlusive disease. Eur Respir J 1996; 9: 346-350.

19. Steele PM, Fuster V, Cohen M, Ritter DG, McCoon DC. Isolated atrial septal defect with pulmonary vascular obstructive disease - long-term follow-up and prediction of outcome aftersurgical correction. Circulation 1987; 76: 1037-1047.

20. Chazova I, Loyd JE, Zhdanov VS, Newman JH, Belenkov Y, Meyrick BO. Pulmonary artery adventitial changes and venous involvement in primary pulmonary hypertension. Am J Pathol 1995; 146: 389-397.

21. White CW. Treatment of hemangiomatosis with recombinant interferon alfa. Semin Hematol 1990; 27(Suppl.): $15-22$.

22. White CW, Wolf SJ, Korones DN, Sondheimer HM, Tosi MF, Yu A. Treatment of childhood angiomatous diseases with recombinant interferon alfa-2a. J Pediatr 1991; 118: 59-66.

23. Nicod P, Moser KM. Primary pulmonary hypertension. The risk and benefit of lung biopsy. Circulation 1989; 80: 1486-1488. 